ISSN 1816-6075 (Print), 1818-0523 (Online)

Journal of System and Management Sciences

Vol. 10 (2020) No. 2, pp. 108-121

DOI: $10.33168 / J$ SMS.2020.0208

\title{
Gesture Design Attribute and Level Value of Social Robot: A User Experience Based Study
}

\author{
Seung-Eun Chung and Han-Young Ryoo \\ Division of Digital Media, Ewha Womans University, 52, Ewhayeodae-gil, \\ Seodaemun-gu, Seoul 03760, Republic of Korea. \\ hyryoo@ewha.ac.kr
}

\begin{abstract}
This study was to verify the attributes of the social robot's gesture design factors that has a significant difference in the user experience and to establish the level values of the attributes. To do so, the attributes and the level value standards for the gesture interface's key design factors have been organized and a user experience survey was conducted through researches on the existing literature and case studies. For the emotional gesture attributes, the level values were categorized as 'pleasure at low arousal', 'pleasure at high arousal', 'displeasure at low arousal', and 'displeasure at high arousal'. Among the communicative expression gesture attributes, the level values were categorized as 'idling, conversation induction and concentration, and empathy'. Lastly, the derived attributes and the level values for the 'emotional gesture' and 'communicative gesture' have been integrated with the ones for the 'functional/semantic gesture' derived on the previous studies; they have been presented as the robot's gesture interface design factors available in the aspect of the user experience.
\end{abstract}

Keywords: Social Robot, gesture Interface, design attribute and level value, user experience

\section{Introduction}

Gesture is used as a medium that conveys emotions or characteristics. It also works as a key role for the robot to feel as a social existence, so the gesture design studies in the social robot are very important. From the list of the gestures that appear in the social robots, the mostly realized gesture factors are the functional/semantic gestures, emotional gestures, and communicative gestures depending on the purpose of the gestures. The functional/semantic gestures are the movements used to provide a direct function like moving an object, or to provide information like showing directions. The emotional gestures have been considered as important along with 
the expansion of the social robot market. These gestures usually appear similar to the gestures of human or animal according to the feelings based on the animal behavior. As much observed next, the communicative gestures are the motions that reinforce the communication such as turning the head to the user during the conversation and signaling that it is listening. The segmentation of these gestures according to the specific attributes required to design each factor is needed; it is because the systemization of the interface design attribute can be used as the database for the robot interface designers (Chung, 2018).

Although most of the existing robot studies cover the realization of technically stabilized gestures (Qingshun, et al., 2015), in the social robot studies, studies on the relationships between the robot's emotional factors and the gesture types (Kim and Oh, 2018), and researches on the design of the gesture types appropriate for the robot's personality (Kim, 2008; Kim, et al., 2009) are rising. However, since these researches are limited to particular personalities or emotional factors, the attribute classifications for gesture designs are different; it is now necessary to systemize the attribute standards that can be classified without being limited to the individual context. In the perspective of the user experience design, these attributes are the user experience factors and the attribute classification standards and its level values should be classified at a level where a user experience difference exists. It is because, in the user experience design, when the designer selects the design factors and decides to express at which level, it all should be determined in the perspective of the user experience (Garrett, 2003)

In this research, the gestures will be investigated by factors according to the purpose for the gesture design systemization that can be used in the user design perspective. Also, in addition to the functional/semantic gestures that were discussed in the previous research, the gestures that express emotions and that provides communication will be examined in this study.

In order to do so, literature researches are to be conducted first to see what kinds of attributes each gesture factor can be categorized into. Next, through trends studies, the attribute standards that reflect various cases in the social robot cases are to be defined and their sub-level values are to be classified as well. A user survey was conducted regarding the organized values and, in turn, the results were used to suggest the attributes and the level values that create a significant difference in the user experience aspect. Finally, by organizing with the level values in regards to the functional/semantic gesture (Chung, et al., 2020) derived from the previous study, the robot's gesture interface design factors that can be used in the aspect of the user experience are presented.

\section{Literature Research on Gesture Interface Design Factor Classification}

\subsection{Emotional Gesture Classification Research}

The studies on the gestures to express emotions have been actively rising in the aspect of the emotional interaction. Traditionally, the robot's emotional expressions are usually referred to Ekman's six basic emotions of happiness, anger, fear, disgust, sadness and surprise and tiredness, accepting and stem can be added (Miwa, et al., 2003). Lee et al(2014) analyzed and used this model in a study on the robot's social interaction in the aspect of the type of motivation and the feedback on the goal achievement. They divided the type of emotions 
that are experienced depending on the value utility regulatory focus (i.e. improvement vs. defense) and the level of achievement (i.e. not achieved vs. achieved). The emotions were divided into dejection, cheerfulness, agitation, quiescence and they were used as the emotional classification standards of the model for the robot's social interaction (Lee, et al., 2014)

These researches have been derived the expressional emotions based on the studies that analyzed and spatialized the emotion's basic factors, and one of the commonly used model is Russell's two-dimensional space model. He suggested how 28 emotions were distributed according to the pleasure-displeasure and degree of arousal dimensions (Russell, 1980). In this research, the emotional attributes have been grouped as pleasure at high arousal, pleasure at low arousal, displeasure at low arousal, and displeasure at high arousal. Then, checking the methods and types observed in the robot cases, whether the specific level value can be used in the robot gestures needs to be examined.

\subsection{Communicative Gesture Classification Research}

The communicative gestures are the gestures used to reinforce the communication between the robot and the user. Chung, Kanda, and $\operatorname{Kim}(2009)$ said in a study that these gestures could be divided into 'Idling', 'Human observation', 'Listening to Human', ' Expecting human's reaction ', 'Creating an mood for human', according to the humanoid robot motion's speech-less gestures (Jung, May 2009) This study is meaningful in the respect that, whether speech-based gestures (i.e. motions that the robot takes while speaking) or speechless gestures (i.e. motions that the robot takes when silent), it draws communication by indicating its listening to human, expressing its existence or creating a mood.

These gestures are to induce a continuous interaction with humans and have a very important impact on improving social relations in the cognitive and emotional aspects. Accordingly, materialization of the robot's gestures to lead communication from social robots are being actively arising; however, there are not enough theoretical studies to organize the concepts. For that reason, based on the existing communicative gesture case studies, the system needs to be organized at the conceptual level in this study

Table. 1: Gesture interface factor's classification factors found in the literature

\begin{tabular}{|l|l|}
\hline \multicolumn{1}{|c|}{ Factor } & \multicolumn{1}{c|}{ Classification } \\
\hline Emotional Gesture & $\begin{array}{l}\text { Conceptual classification: Pleasure-high arousal, Pleasure-low arousal, } \\
\text { Displeasure-low arousal, Displeasure-high arousal; } \\
\text { Detailed types: Happy, Delighted, Excited, Astonished, Aroused, Tense, } \\
\text { Alarmed, Angry, Afraid, Annoyed, Distressed, Frustrated, Miserable, Sad, } \\
\text { Gloomy, Depressed, Bored, Droopy, Tired, Sleepy, Calm, Relaxed, Satisfied, } \\
\text { At ease, Content, Serene, Glad, Pleased }\end{array}$ \\
\hline $\begin{array}{l}\text { Communicative } \\
\text { Gesture }\end{array}$ & $\begin{array}{l}\text { Idling, Human observation, Listening to Human, Expecting human's reaction, } \\
\text { Creating a mood for human }\end{array}$ \\
\hline
\end{tabular}

A literature research was conducted in order to understand what classification concepts are commonly discussed to conceptually classify and sort out the useful attributes when designing each gesture type. Next, based on the main classification factors found in the literature study, the social robot case studies that are available at 
the moment have been thoroughly examined to organize the attributes and the sublevel value for each attribute reflecting the current trends

\section{Attributes and level value organization of the gesture design factors reflecting the social robot case studies}

In this study, based on the classification factors derived from the literature analysis, the design factors' attributes and their level values, that reflect the currently being materialized and studied robot trends, have been organized. At first, the robot design cases that provide gestures among the social service robots were examined (Chung, et al., 2018; Park and Ryoo, 2017). In the aspect of emotional gestures, and communicative gestures and the specific case studies with various gestures were organized. For the human type robots, Pepper, Robi, Atom, Nao and EMIEW3 have been collected as they have limbs or have highly free joints of arms and torso. As for the more abstract robots that are without limbs and simplified to have only head and torso, JIBO, Zenbo and Buddy have been gathered. Aibo, ZOOMER and OHANAS were picked as the animal type robots. Then, these cases were categorized by matching them with the classification factor keywords derived from the existing literature. The cases were grouped through the Affinity Diagramming and when the concepts were redundant, the classification factors have been integrated. Moreover, the classification factors that only had a few cases or none to match, they were eliminated. The functional/semantic gesture factors discussed in the previous studies, the attributes were classified as concept instruction, behavior description, behavior mimicry, and functional performance and their level values (Kim, et al., 2009). The emotional gesture and communicative gesture factor's attributes and their level values, which were derived through case studies in this study, are as follows.

\subsection{Emotional Gesture Case Studies}

\section{(1) Pleasure at High Arousal}

The attribute of pleasure at high arousal include the level values of 'excited', 'happy', and 'delighted'. First of all, 1-1. 'excited' means the emotional status when one is pleased, enthusiastic and cannot relax. The animal type robot Zoomer, for example, expresses its excitement by shaking its head and torso and making sounds (i.e. 1-1 in Fig. 1). 1-2. 'Happy' is the condition one is feeling very satisfied and pleased. When JIBO feels happy, it will turn its body left and right and show a smiley face on the screen to express happiness (i.e. 1-2 in Fig. 1). 1-3. 'Delighted' indicates that one is very happy for something that has happened to someone and feels celebrative towards him or her. Pepper, a human type robot, celebrates the user's birthday by putting its arms up and shaking them to express its delightedness (i.e. 1-3 in Fig. 1).

\section{(2) Pleasure at Low Arousal}

The attributes of pleasure at low arousal include the level values of 'serene' and 'satisfied'. First, 2-1. 'serene' tells that one is at its ease without any worry or problems. The abstract type robot JIBO will purr towards the user when the user strokes its head (i.e. 2-1 in Fig. 1). Next, 2-2. 'satisfied' indicates the feeling one can have when there is nothing else needed and everything is sufficient. When JIBO is 
very satisfied with the fully charged battery, it will show the image of the fully charged battery on the screen and use sound effects to articulate its satisfaction (i.e. 2-2 in Fig. 1).

\section{(3) Displeasure at Low Arousal}

The attributes of displeasure at low arousal contain the level values of 'sad', 'disappointed', 'sorry', and 'tired'. First, 3-1. 'sad' represents the feelings that one can have when something tragic or terrible happened. The abstract robot Buddy will tear up making sobbing sounds with lowered mouth to show empathy towards the user's sad situation (i.e. 3-1 in Fig. 1). 3-2. 'Disappointed' denotes one's unsatisfied feeling when something did not happen as expected. Another abstract type robot Cozmo will bow its head and put its arms down when it loses a game (i.e. 3-2 in Fig. 1). 3-3. 'Sorry' is the feeling when one is not feeling comfortable and apologizing towards someone. The abstract type robot JIBO expresses its sorriness when it did not understand what the user is saying by bowing its head and look back up (i.e. 3-3 in Fig. 1). Lastly, 3-4. 'tired' is the condition when one is very exhausted physically or mentally. The human type robot Robi shows its tiredness after dancing by bowing its head and stretching the both arms down (i.e. 3-4 in Fig. 1).

\section{(4) Displeasure at High Arousal}

The attributes of displeasure at high arousal comprise the level values of 'angry', 'afraid', and 'surprised'. First, 4-1. 'angry' indicates the condition when one is feeling dislike and upset. When the abstract type robot Cozmo gets angry, it will hit the floor several times with its arms, shaking its head up and down with an angry face or throwing a cube in front after losing a game (i.e. 4-1 in Fig. 1). 4-2. 'Afraid' is the feeling one can have in the unwanted situation being frightened and scared. If someone holds the abstract type robot Cozmo high up in the air, it will make a scared face and shake its arms and body fast (i.e. 4-2 in Fig. 1). Lastly, 4-3. 'surprised' is the feeling of unease when something unexpected or unusual happens. The human type robot Nao as well as the abstract type robot Zenbo express their surprised feelings by looking at the user with wide open eyes in the reaction of an unexpected situation (i.e. 4-3 in Fig. 1).

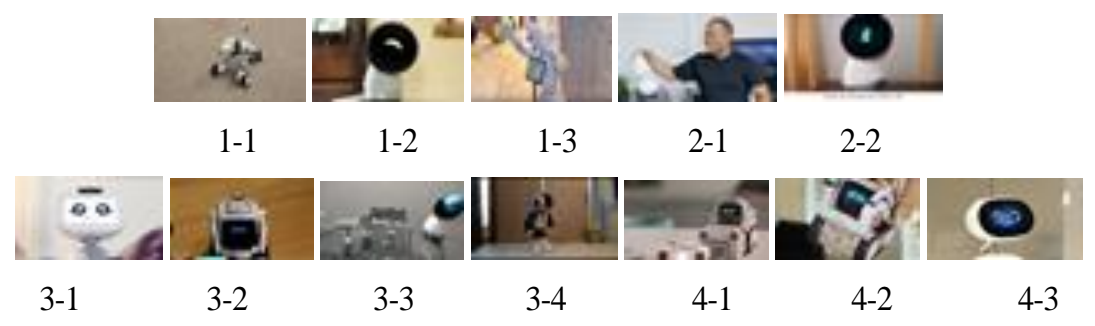

Fig. 1: Case image for emotional gestures 


\subsection{Communicative Gesture Classification Research}

The communicative gestures are hard to classify as different concepts, so they have been subdivided under one communicative attribute which include the level values of 'idling', 'mood induction', 'attention attraction', 'attention expression', 'concentration', and 'empathy'. First, 1-1. 'idling' indicates that when the robot is not performing a specific function, it naturally shows that it is still alive through periodic gestures. When there is no interaction with the user, the abstract type robot COZMO turns its body left and right to reveal that it is still functional at any time (i.e. 1-1 in Fig. 2). 1-2. 'Mood induction' represents the inducing expression used to create a comfortable mood for the user to naturally have a conversation. The abstract type robot Zenbo turns its head towards the user with a light smile to generate a comfortable environment for conversation (i.e. 1-2 in Fig. 2). 1-3. 'Attention attraction' indicates the actively inducing expression for the user's attention. The human type robot EMIEW3 brings its arms high up and swing them left to right to get attention when distributing the coupons at a shopping center (i.e. 1-3 in Fig. 2). 1-4 'Attention' indicates the expressions to show its readiness to listen at the beginning of a conversation. When the abstract type robot JIBO is called by the user, it will show that it is waiting for the next words by holding its head and body towards the user (i.e. 1-4 in Fig. 2). 1-5. 'Concentration' reveals that it is focusing on the conversation at the moment. The human type robot Pepper will express its concentration by turning its ear a little bit closer to the user (i.e. 1-5 in Fig. 2). 1-6. 'Empathy' represents the expressions used to prove the agreement on the contents of the conversation and to allow it to continue. The human type robot Robi expresses its agreement on the user's statement by nodding its head (i.e. 1-6 in Fig. 2).

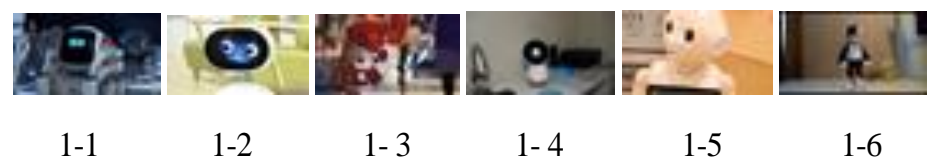

Fig. 2: Case image for communicative gestures

\section{Derivation of social robot design factors and level value based on the user experience}

\subsection{Research Summary}

The user experience was to be measured in this study concerning the previously organized robot gesture interface design factor attributes and the sub-level values. The specifically chosen user experience were the functional/service-wise experience, interactive experience, and emotional experience and they were measured on a seven-point Likert scale. Several cases and questions regarding the organized level values were presented through a web survey system, and a total of 220 participants, including male and female in the 20 s to 40 s, have been participated in the survey. 
The analysis of the survey was first started with the differences in the user experiences for the level values of each attribute to be verified by using the OneWay Analysis of Variance.

When there was a difference between the levels, it was verified by the Scheffe test, a post-hoc comparison analysis. The Scheffe test is to check the existence of the difference in the attributes by the F test of One-Way Analysis of Variance and through multiple comparison, to figure out which group had differences. When the calculated significance probability was less than 0.05 value, it was determined to have a difference between the levels. When the Scheff test results indicated that the levels had no difference, they were decided to be the same group and labelled with the same alphabet, and when there was a difference, they were labelled with different alphabets.

When organizing the results, if the level values for each attribute did not have differences in all the functional/service-wise experience, interactive experience and emotional experience as well as when there were level values to be grouped together, the level values were integrated into one. Furthermore, when only one level value existed under one attribute after all the level values were merged into one, that attribute was eliminated.

\subsection{Results of Emotional Gestures}

\section{(1) User Experience Evaluation on Pleasure at High Arousal}

The average values of the pleasure at high arousal, which are divided into 1-1. Excited, 1-2 happy, and 1-3. Delighted, were compared. There was no statistically significant difference towards all A) functional/service-wise experience, B) interactive experience and C) emotional experience. Therefore, the divided level values of the pleasure at high arousal have been combined to 'happy and delighted'.

Table. 2: Evaluation on pleasure at High Arousal

\begin{tabular}{|c|c|c|c|c|}
\hline UX & No. & Mean & $\mathbf{F}$ & $\mathbf{P}$ \\
\hline \multirow{3}{*}{ Functional } & $1-1$ & 4.359 & \multirow{3}{*}{1.07} & \multirow{3}{*}{.334} \\
\hline & $1-2$ & 4.523 & & \\
\hline & $1-3$ & 4.514 & & \\
\hline \multirow{3}{*}{ Interaction } & $1-1$ & 4.459 & \multirow{3}{*}{.29} & \multirow{3}{*}{.752} \\
\hline & $1-2$ & 4.550 & & \\
\hline & $1-3$ & 4.523 & & \\
\hline \multirow{3}{*}{ Emotional } & $1-1$ & 4.655 & \multirow{3}{*}{.35} & \multirow{3}{*}{.706} \\
\hline & $1-2$ & 4.650 & & \\
\hline & $1-3$ & 4.746 & & \\
\hline
\end{tabular}

\section{(2) User Experience Evaluation on Pleasure at Low Arousal}

The average values of the pleasure at low arousal, which are divided into 2-1. Serene and 2-2 satisfied, have been compared. There was no statistically significant difference towards all A) functional/service-wise experience, B) interactive 
experience and C) emotional experience. Thus, the divided level values of the pleasure at low arousal have been merged to 'satisfied or serene'.

Table. 3: Evaluation on Pleasure at Low Arousal

\begin{tabular}{|c|c|c|c|c|}
\hline UX & No. & Mean & F & P \\
\hline \multirow{2}{*}{ Functional } & $2-1$ & 4.305 & \multirow{2}{*}{1.25} & \multirow{2}{*}{.265} \\
\cline { 2 - 3 } & $2-2$ & 4.443 & & \\
\hline \multirow{2}{*}{ Interaction } & $2-1$ & 4.364 & \multirow{2}{*}{.35} & .555 \\
\cline { 2 - 3 } & $2-2$ & 4.439 & & \multirow{2}{*}{.59} \\
\hline \multirow{2}{*}{ Emotional } & $2-1$ & 4.477 & & .445 \\
\cline { 2 - 3 } & $2-2$ & 4.577 & & \\
\hline
\end{tabular}

\section{(3) User Experience Evaluation on Displeasure at Low Arousal}

The average values of the displeasure at low arousal, which are divided into 3-1. Sad, 3-2. Unsatisfied, 3-3. Sorry, 3-4. Tired, were compared. There was no statistically significant difference towards all A) functional/service-wise experience, B) interactive experience and C) emotional experience. Hence, the divided level values of displeasure at low arousal have been integrated to 'sorry or sad'.

Table. 4: Evaluation on displeasure at low

\begin{tabular}{|c|c|c|c|c|}
\hline UX & No. & Mean & F & P \\
\hline \multirow{4}{*}{ Functional } & $3-1$ & 4.296 & & \\
\cline { 2 - 3 } & $3-2$ & 4.271 & \multirow{2}{*}{1.30} & .187 \\
\cline { 2 - 3 } & $3-3$ & 4.361 & & \\
\cline { 2 - 3 } Interaction & $3-4$ & 4.084 & & \multirow{2}{*}{.100} \\
\cline { 2 - 3 } & $3-1$ & 4.364 & & \\
\cline { 2 - 3 } & $3-2$ & 4.289 & & \\
\cline { 2 - 3 } & $3-3$ & 4.334 & & \multirow{2}{*}{.09} \\
\hline \multirow{4}{*}{ Emotional } & $3-4$ & 4.059 & & \\
\cline { 2 - 3 } & $3-1$ & 4.243 & & \\
\cline { 2 - 3 } & $3-2$ & 4.277 & & \\
\cline { 2 - 3 } & $3-4$ & 4.264 & & \\
\hline
\end{tabular}

\section{(4) User Experience Evaluation on Displeasure at High Arousal}

The average values of the displeasure at high arousal, which are divided into 4-1. Angry, 4-2. Afraid, 4-3. Surprised, have been compared. There was statistically significant difference towards both A) functional/service-wise experience and B) interactive experience with a p.value of greater than 0.01 . The Schaffe test showed that 'angry' was in group 'b', 'afraid' was in group 'ab', and 'surprised' was in group 'b'. In the C) Emotional experience, a statistically significant difference existed in the communication with a p.value greater than 0.01. According to the Schaffe test, 'angry' and 'afraid' fell into the same group a and 'surprised' fell into group 'b'. 
Since the divided level values all had differences in the functional/service-wise experience, interactive experience and emotional experience, the current level values have been kept as is.

Table. 5: Evaluation on Displeasure at High Arousal

\begin{tabular}{|c|c|c|c|c|c|c|c|c|}
\hline \multirow{2}{*}{ UX } & \multirow{2}{*}{ No. } & \multirow{2}{*}{ Mean } & \multicolumn{4}{|c|}{ Scheffe } & \multirow{2}{*}{$\mathbf{F}$} & \multirow{2}{*}{$\mathbf{P}$} \\
\hline & & & Group & No. & MD & $\mathbf{P}$ & & \\
\hline \multirow{6}{*}{ Functional } & \multirow{2}{*}{$4-1$} & \multirow{2}{*}{3.772} & \multirow{2}{*}{$\mathrm{a}$} & $4-2$ & -.114 & .712 & \multirow{6}{*}{5.63} & \multirow{6}{*}{.004} \\
\hline & & & & $4-3$ & -.445 & .006 & & \\
\hline & \multirow{2}{*}{$4-2$} & \multirow{2}{*}{3.886} & \multirow{2}{*}{$a b$} & 4-1 & .114 & .712 & & \\
\hline & & & & $4-3$ & -.332 & .056 & & \\
\hline & \multirow{2}{*}{$4-3$} & \multirow{2}{*}{4.218} & \multirow{2}{*}{ b } & $4-1$ & .445 & .006 & & \\
\hline & & & & $4-2$ & .332 & .056 & & \\
\hline \multirow{6}{*}{ Interaction } & \multirow{2}{*}{$4-1$} & \multirow{2}{*}{3.784} & \multirow[b]{2}{*}{$\mathrm{a}$} & $4-2$ & -.073 & .874 & \multirow{6}{*}{5.63} & \multirow{6}{*}{.004} \\
\hline & & & & $4-3$ & -.439 & .008 & & \\
\hline & \multirow{2}{*}{$4-2$} & \multirow{2}{*}{3.857} & \multirow{2}{*}{$\mathrm{a}$} & $4-1$ & .073 & .874 & & \\
\hline & & & & $4-3$ & -.366 & .034 & & \\
\hline & \multirow{2}{*}{$4-3$} & \multirow{2}{*}{4.223} & \multirow{2}{*}{ b } & 4-1 & .439 & .008 & & \\
\hline & & & & $4-2$ & .366 & .034 & & \\
\hline \multirow{6}{*}{ Emotional } & \multirow{2}{*}{$4-1$} & \multirow{2}{*}{3.687} & \multirow[b]{2}{*}{$\mathrm{a}$} & $4-2$ & -.052 & .935 & \multirow{6}{*}{8.50} & \\
\hline & & & & $4-3$ & -.532 & .001 & & \\
\hline & 4-? & 3739 & a & $4-1$ & .052 & .935 & & 000 \\
\hline & & & $\mathrm{a}$ & $4-3$ & -.480 & .004 & & \\
\hline & $4-3$ & 4218 & $\mathrm{~b}$ & 4-1 & .532 & .001 & & \\
\hline & 4-3 & 4.218 & b & $4-2$ & .480 & .004 & & \\
\hline
\end{tabular}

\subsection{Results of Communicative Gestures}

\section{(1) User Experience Evaluation on Communicative Gesture}

The average values of the communication, which are divided into 5-1. Idling, 5-2. Mood induction, 5-3. Attention attraction, 5-4. Attention, 5-5. Concentration, and 56. Empathy, were compared. There was no statistically significant difference in A) functional/service-wise experience and B) interactive experience, but there was in C) emotional experience with a p.value of greater than 0.05. The Scheffe test showed that 'idling fell into group 'a', 'mood induction, attention attraction, attention, and concentration' fell into the same group 'ab', and 'empathy' fell into group ' $b$ '. Therefore, the existing six sub-level values to measure the overall user experience have been adjusted to 'idling', 'conversation induction and concentration' and 'empathy'.

\section{Conclusion}

In this study, the gesture interface design factors' attributes that can be used in the social robots and the level values have been organized based on the literature researches on the robot's gesture interface design factor's classification. Then, the 
classifications found in the literature were verified if they trigger any significant difference in the user experience aspect and the gesture interface design factors' attributes and their sub-level values that affect the user experience were suggested.

Table. 6: Evaluation on Communicative Gesture

\begin{tabular}{|c|c|c|c|c|c|c|c|c|c|c|c|}
\hline \multirow{2}{*}{$\mathbf{U X}$} & \multirow{2}{*}{ No. } & \multirow{2}{*}{ Mean } & \multicolumn{7}{|c|}{ Scheffe } & \multirow{2}{*}{$\mathbf{F}$} & \multirow{2}{*}{$\mathbf{P}$} \\
\hline & & & Group & No. & MD & $\mathbf{P}$ & No. & MD & $\mathbf{P}$ & & \\
\hline \multirow{6}{*}{$\mathrm{F}^{*}$} & 5_1 & 4.539 & \multicolumn{7}{|l|}{-} & \multirow{6}{*}{1.43} & \multirow{6}{*}{.211} \\
\hline & $5 \_2$ & 4.593 & \multicolumn{7}{|l|}{-} & & \\
\hline & 5_3 & 4.750 & \multicolumn{7}{|l|}{-} & & \\
\hline & 5_4 & 4.787 & \multicolumn{7}{|l|}{-} & & \\
\hline & 5_5 & 4.748 & \multicolumn{7}{|l|}{-} & & \\
\hline & 5_6 & 4.755 & \multicolumn{7}{|l|}{-} & & \\
\hline \multirow{6}{*}{$I^{*}$} & 5_1 & 4.541 & \multicolumn{7}{|l|}{-} & \multirow{6}{*}{1.52} & \multirow{6}{*}{.179} \\
\hline & 5_2 & 4.559 & \multicolumn{7}{|l|}{-} & & \\
\hline & $5 \_3$ & 4.139 & \multicolumn{7}{|l|}{-} & & \\
\hline & 5_4 & 4.787 & \multicolumn{7}{|l|}{-} & & \\
\hline & 5_5 & 4.677 & \multicolumn{7}{|l|}{-} & & \\
\hline & 5_6 & 4.775 & \multicolumn{7}{|l|}{-} & & \\
\hline \multirow{18}{*}{$\mathrm{E}^{*}$} & \multirow{3}{*}{$5 \_1$} & \multirow{3}{*}{4.359} & & 9_2 & -.300 & .351 & $9 \_5$ & -.361 & .153 & & \\
\hline & & & $\mathrm{a}$ & 9_3 & -.305 & .333 & 9_6 & -.441 & .035 & & \\
\hline & & & & 9_4 & -.330 & .243 & & & & & \\
\hline & & & & 9_1 & .300 & .351 & $9+5$ & -.061 & .999 & & \\
\hline & $5 \_2$ & 4.659 & $a b$ & 9_3 & -.005 & 1.00 & $9+6$ & -.141 & .942 & & \\
\hline & & & & 9_4 & -.030 & 1.00 & & & & & \\
\hline & & & & 9_1 & .305 & .333 & 9_5 & -.059 & .999 & & \\
\hline & $5 \_3$ & 4.664 & $a b$ & 9_2 & .005 & 1.00 & 9_6 & -.136 & .949 & & \\
\hline & & & & 9_4 & -.025 & 1.00 & & & & & \\
\hline & & & & 9_1 & .330 & .243 & $9 \_5$ & -.032 & 1.00 & 2.82 & .015 \\
\hline & 5_4 & 4.689 & $a b$ & 9_2 & .030 & 1.00 & $9 \_6$ & -.111 & .979 & & \\
\hline & & & & $9 \_3$ & .025 & 1.00 & & & & & \\
\hline & & & & 9_1 & .361 & .153 & 9_4 & .032 & 1.00 & & \\
\hline & 5_5 & 4.721 & $a b$ & 9_2 & .061 & .999 & 9_6 & -.080 & .996 & & \\
\hline & & & & 9_3 & .057 & .999 & & & & & \\
\hline & & & & 9_1 & .441 & .035 & 9_4 & .111 & .979 & & \\
\hline & 5_6 & 4.800 & $\mathrm{~b}$ & $9 \_2$ & .141 & .942 & 9_5 & .080 & .996 & & \\
\hline & & & & 9_3 & .136 & .949 & & & & & \\
\hline
\end{tabular}

* F: Functional, I: Interaction, E: Emotional

As for the emotional gesture, since there is no significant difference in the user experience evaluation for 'excited', 'happy' and 'delighted' in 'pleasure at high 
arousal', they have been merged to 'happy or delighted'. In the attribute of 'pleasure at low arousal', a significant difference was not found for both 'serene' and 'satisfied', these level values have been combined to 'satisfied or serene'. Also, in the attribute of 'displeasure at low arousal', there was no significant difference in the experience evaluation for all 'sad', 'unsatisfied', 'sorry' and 'tired'; they have been integrated to 'sorry or sad'. In short, the user was not sensitive to the differences in the gestures that reveal the robot's emotions. Lastly, 'displeasure at high arousal' had a difference in the divided level values so that existing level values of 'angry' and 'afraid' have been maintained. However, as the users had negative evaluations of below the average value towards the gestures to express 'angry' and 'afraid', these two level values had been deleted from the design factor level values when it comes to gesture designing. Besides, for the emotional gesture factors, the attributes were classified into four different types depending on the level of arousal with pleasure and displeasure; they have been integrated into one emotional attribute with four level values. It is interpreted as that the user takes the emotional gestures according to the context rather than the various forms; thus, when designing emotional gestures, it seems to be more effective to design with a broad division instead of a narrow division with detailed level values.

The communicative gesture's level values were divided into 'idling, 'mood induction', 'attention attraction', 'attention', 'concentration' and 'empathy' and they were modified to 'idling', 'conversation induction and concentration' and 'empathy'. This can be inferred that the passive or active gestures to create a mood to induce the user to talk or the gestures to show that the robot is paying attention and wait for the user to talk and listen are all understood as waiting for a conversation.

In the previous studies on the functional/semantic gestures[7], the level values of 'concept instruction', 'item/sequential instruction, location instruction, quantity instruction', have been adjusted to 'item's sequential/quantity instructions' and 'directional instructions'. In other words, the item/sequential instruction was understood as the same as the quantity instruction and this is because the quantity concept can be compared in the sequential order. Therefore, the quantity concept can be included in the item/sequential concept. Another example is that the level values of 'behavior description', which are 'usage behavior descriptions', 'situational behavior description' and 'symbolic behavior description', have been modified to 'usage and situational behavior descriptions' and 'symbolic behavior descriptions'. This can be interpreted as that the user's perception can be very different in regards to the usage of a tool in a certain situation.

By organizing with the attributes of the functional/semantic gestures[7] derived from the previous paper, the robot gesture interface design attributes and their level values that should be considered by the designer in the aspect of the user experience are organized in the following Table 7. 
Table. 7: E gesture design factors' attributes and their level values

\begin{tabular}{|c|c|c|}
\hline Attribute & Level Value & Definition \\
\hline \multirow{2}{*}{$\begin{array}{l}\text { Concept } \\
\text { Instruction }\end{array}$} & $\begin{array}{l}\text { Sequential/quantity } \\
\text { Instruction }\end{array}$ & $\begin{array}{l}\text { Instruction on the concept related to the sequence or } \\
\text { quantity of the item }\end{array}$ \\
\hline & Scale Instruction & Instruction on the concept related to the size or quantity \\
\hline \multirow{3}{*}{$\begin{array}{l}\text { Behavior } \\
\text { Description }\end{array}$} & $\begin{array}{l}\text { Usage Behavior } \\
\text { Description }\end{array}$ & $\begin{array}{l}\text { Behavior description that uses a tool related to a } \\
\text { function; this behavior does not complete the function } \\
\text { but emphasizes the meaning of the function itself }\end{array}$ \\
\hline & $\begin{array}{l}\text { Situational } \\
\text { Behavior } \\
\text { Description } \\
\end{array}$ & $\begin{array}{l}\text { Behavior description that occurs in a particular } \\
\text { situation and this is the stress the meaning of the } \\
\text { situation or to help understand }\end{array}$ \\
\hline & $\begin{array}{l}\text { Symbolic Behavior } \\
\text { Description }\end{array}$ & $\begin{array}{l}\text { Movement that is idiomatically understandable } \\
\text { expressions }\end{array}$ \\
\hline \multirow{3}{*}{$\begin{array}{l}\text { Behavior } \\
\text { Mimicry }\end{array}$} & $\begin{array}{l}\text { Prototype Behavior } \\
\text { Mimicry }\end{array}$ & $\begin{array}{l}\text { Common sense behavior imitation for a prototype of a } \\
\text { person or an animal }\end{array}$ \\
\hline & $\begin{array}{l}\text { Biological Behavior } \\
\text { Mimicry }\end{array}$ & $\begin{array}{l}\text { Common sense behavior to imitate the characteristics } \\
\text { of the robot prototype, such as female, male, a child, an } \\
\text { adult, or an elderly }\end{array}$ \\
\hline & $\begin{array}{l}\text { Personality } \\
\text { Behavior Mimicry }\end{array}$ & $\begin{array}{l}\text { Common sense behavior that defines the robot's unique } \\
\text { personality such as extroverted, gentle, or cute }\end{array}$ \\
\hline \multirow{2}{*}{$\begin{array}{l}\text { Functional } \\
\text { Performance }\end{array}$} & $\begin{array}{l}\text { Direct Behavior } \\
\text { Performance }\end{array}$ & Direct action taken to perform a function \\
\hline & $\begin{array}{l}\text { Proxy Behavior } \\
\text { Performance }\end{array}$ & $\begin{array}{l}\text { Action taken on behalf of the user to perform a } \\
\text { function }\end{array}$ \\
\hline \multirow{4}{*}{ Emotion } & happy and delighted & $\begin{array}{l}\text { Feeling very satisfied and pleased, or feeling excited for } \\
\text { something that has happened to someone and feels } \\
\text { celebrative towards him or her }\end{array}$ \\
\hline & satisfied or serene & $\begin{array}{l}\text { Feeling that nothing else is needed and everything is } \\
\text { sufficient }\end{array}$ \\
\hline & sorry or sad & $\begin{array}{l}\text { Feeling unpleasant when something terrible happened } \\
\text { or feeling apologizing towards someone }\end{array}$ \\
\hline & surprised & $\begin{array}{l}\text { Feeling of unease due to something unexpected or } \\
\text { unusual happened }\end{array}$ \\
\hline \multirow{3}{*}{$\begin{array}{l}\text { Communica } \\
\text {-tion }\end{array}$} & Idling & $\begin{array}{l}\text { Taking periodic gestures when not in operation to show } \\
\text { liveliness }\end{array}$ \\
\hline & $\begin{array}{l}\text { conversation } \\
\text { induction and } \\
\text { concentration }\end{array}$ & $\begin{array}{l}\text { Gestures that show it is waiting or concentrating on the } \\
\text { conversation to induce a conversation or to continue }\end{array}$ \\
\hline & Empathy & $\begin{array}{l}\text { Gestures that reveal agreement to actively continue the } \\
\text { conversation }\end{array}$ \\
\hline
\end{tabular}

Researches on the systemization of the robot gesture design factors is very important as the necessity of the robot design base study's standardization is increasing. This research was to examine the impact of the robot gesture design 
factors in the user experience aspect; especially, it is meaningful that specifically the functional/service-wise experience, interactive experience, and human emotional experience were scrutinized as the user experience is very general. In the future researches, what relationships the gesture design factors that are derived from this study and the detailed sub-user experience attributes have should be further investigated. As a fundamental research for them, this study is expected to contribute to offer a guideline for the social robot design.

\section{Acknowledgements}

This research was supported by Basic Science Research Program through the National Research Foundation of Korea(NRF) funded by the Ministry of Education(No.2017R1A6A3A11031044).

\section{References}

Chung, S. E. and Ryoo, H. Y. (2018). Study on the level value standard of the robot appearance interface factor for user experience design, International Journal of Advanced Science and Technology, 113, 153-164.

Chung, S. E. and Ryoo, H. Y. (2018). Aural and behavioral factor research for robot design. International Journal of Multimedia and Ubiquitous Engineering, 13(2), 1-6

Chung, S. E. and Ryoo, H. Y. (2020). Functional/semantic gesture design factor studies on social robot for user experience design, International Journal of Smart Home, 14(1), 1-8.

Garrett, J. J. (2003). The elements of user experience, New Riders.

Jung, J., Kanda, T. and Kim, M. (May 2009). Motion design guideline for a humanoid robot, In KSDS Conference Proceeding, Korean Society of Design Science, May 2009. 190-191.

Kim, S. and Oh, D. (2018). The Kinesics for emotional expression in the household social robot - Focus on the head movement of the robot, The Korean Society of Science \& Art, 35, 69-82.

Kim, H. (2008). A study on robot gesture design based on myers-briggs type indicator: focused on matching personality of a robot expressed through gestures to tasks, M.S. thesis. KAIST. Republic of Korea. 
Kim, J., Kwak, S. S. and Kim, M. (2009). Entertainment robot personality design based on basic factors of motions, Journal of Korean Society of Design Science, 23(1), 5-14.

Lee, W. H., Park, J. W., Kim, W. H., Lee, H. S. and Chung, M. J. (2014). Robot's motivational emotion model with value effectiveness for social human and robot interaction. Journal of Institute of Control, Robotics and Systems, 20(5), 503-512.

Miwa, H., Okuchi, T., Itoh, K., Takanobu, H. and Takanishi, A. (2003). A new mental model for humanoid robots for human friendly communication introduction of learning system, mood vector and second order equations of emotion. In 2003 IEEE International Conference on Robotics and Automation. 3, 3588-3593.

Park, J. and Ryoo, H. Y. (2017). Service classification of home robot. International Journal of Smart Home. 11(11), 41-46.

Qingshun, T., Chunfu, W., Yuanhui, Y., Guodong, L. and Fengyu, Z. (2015). Design and implementation of fractional order controller for service robots. International Journal of Control and Automation, 8(5), 209-220.

Russell, J. A. (1980). A circumflex model of affect. Journal of personality and social psychology, 39(6), 1161. 